\title{
Oral non-absorbable antibiotics for colorectal surgery
}

\author{
R. Nelson
}

Published online: 9 November 2011

(C) Springer-Verlag 2011

At a recent meeting of the American Society of Colon and Rectal Surgeons, I asked several old friends about the use of oral antibiotics in antibiotic prophylaxis for elective colon and rectal surgery. I assumed I was resurrecting a dusty old memory, as it had been probably 20 years since I had prescribed oral antibiotics for one of my patients. I think the thing that stopped me from doing so was opening a surgical specimen and seeing the tablets still in the colon and so poorly digested that the numbers were still clearly legible on the intact pills. I felt that there could be no certainty with orals as to dosing and timing. I assumed that the rest of the world had also gone that way. A further change would have been an even greater effect on this practice and that is the origin of the Cochrane Collaboration. This organization has had an effect on the practice of medicine the world over that cannot be calculated. Relevant reviews of the use of antibiotics include a review that showed that mechanical bowel cleansing prior to surgery, something patients hated, was of no clinical benefit [1]. The Cochrane trauma literature also strongly supported this point, finding that fecal diversion of an injured uncleansed colon versus immediate repair could actually result in a worse clinical outcome, even if the morbidity of stoma closure were ignored [2]. Economic changes also had an effect with same day admission for surgery, further disrupting bowel preps and oral schedules. Here, in the UK, mechanical bowel cleansing is now a thing of the past, except that there are many surgeons who still give an enema before an anterior resection, though the data for this practice are lacking. In any case, with the disappearance of oral bowel cleansing, the use of oral antibiotics

R. Nelson $(\bowtie)$

Department of Colorectal Surgery, Northern General Hospital, Sheffield S5 7AU, UK

e-mail: rick.nelson@sth.nhs.uk seemed illogical, and in many areas, the practice was ceased. And so, it was with a bit of wistful nostalgia that my colleagues talked about their fondness for oral antibioticsthe luminal versus tissue effect.

Yet apparently, the use of oral antibiotics (much less the persistent use of mechanical cleansing of the colon) has not disappeared from other areas, as is demonstrated in this very well researched and written systematic review of oral non-absorbable antibiotics [3]. This was seen most clearly in reference 36 from this review, a survey of bowel preparation for elective colorectal surgery in the state of Michigan in the USA [4]. Eighty-six percent of patients in Michigan received a mechanical prep (very different from here), and almost half of them received oral non-absorbable antibiotics (though one would have thought that the reason for cleansing the colon was so that they all could get the oral antibiotic). Curious.

There is much more of interest in this review. The search strategy found four studies on antimicrobial prophylaxis in colorectal surgery, within which this topic is covered that had not been found in two previous searches for the Cochrane review [5]. This shows how critical this component of systematic review is. I will certainly be following the authors' lead in the update of this Cochrane review, which is due this year. They used as a primary endpoint surgical site infection, which is an excellent surrogate for most things that can go wrong after colorectal surgery, (it is certainly more accurately detected than anastomotic leak), and found that the combination of parenteral and luminal antibiotics provided better protection against wound infection than parenteral antibiotics alone. This was also the finding of the Cochrane review, which might in this context be viewed as a sensitivity analysis, testing the robustness of the results. The Cochrane review also found the oral plus IV did better than oral alone. 
So what are we to do? Go back to mechanical cleansing (an euphemism), so that we might administer oral antibiotics. How do we measure compliance, timing? A bigger question, not at all intuitive, is do we have to give the mechanical prep? Before you throw the journal in the waste basket, consider how many other intuitive practices have been reversed largely through the sort of science promoted by the Cochrane Collaboration:

Routine nasogastric decompression after laparotomy

Colostomy for penetrating colon injury

Mechanical bowel cleansing

Post-operative antibiotic administration after colon surgery

Hepatic artery chemotherapy after resection of colorectal liver metastases

Cesarean section to prevent anal incontinence compared to vaginal delivery (it doesn't)

So why not oral antibiotics in an "uncleansed" colon? It would be very simple to design a clinical trial to answer that question and so determine in a round about way whether there is a value to cleansing: just treat patients as is normal here in the UK with no prep and IV antibiotics in the anesthetic room and randomize half to have received a few tablets the day before. It would be interesting.

Conflict of interest None.

\section{References}

1. Güenaga KF, Matos D, Wille-Jørgensen P (2011) Mechanical bowel preparation for elective colorectal surgery. Cochrane Database Syst Rev 7 (in press)

2. Nelson R, Singer M (2003) Primary repair for penetrating colon injuries. Cochrane Database Syst Rev 3:CD002247

3. Bellows CF, Mills KT, Kelly TN, Gagliardi G (2011) Combination of oral non-absorbable and intravenous antibiotics versus intravenous antibiotics alone in the prevention of surgical site infections after colorectal surgery: a meta-analysis of randomized controlled trials. Tech Coloproctol. doi:10.1007/s10151-011-0714-4

4. Englesbe MJ, Brooks L, Kubus J et al (2010) A statewide assessment of surgical site infection following colectomy: the role of oral antibiotics. Ann Surg 252:514-519 (discussion 519-520)

5. Nelson RL, Glenny AM, Song F (2009) Antimicrobial prophylaxis for colorectal surgery. Cochrane Database Syst Rev 21:CD001181 